\title{
Full-scale implementation of external nitrification biological nutrient removal at the Daspoort Waste Water Treatment Works
}

\author{
AW Muller ${ }^{1}$, MC Wentzel $^{1 *}$, GB Saayman², SA van de Merwe $^{2}$, CM Esterhuyse $^{2}$, JS Snyman $^{2}$ \\ and GA Ekama ${ }^{1}$ \\ ${ }^{1}$ Water Research Group, Department of Civil Engineering, University of Cape Town, Rondebosch 7701, South Africa \\ ${ }^{2}$ Daspoort Waste Water Treatment Works, City of Tswane Metropolitan Municipality, PO Box 1409, Pretoria 0001, South Africa
}

\begin{abstract}
In the external nitrification (EN) biological nutrient removal (BNR) activated sludge (AS) system, the nitrification process is removed from the main BNRAS system to a fixed media system external to the AS system (Hu et al., 2003). The ENBNRAS system provides considerable advantages over the conventional BNRAS system, e.g. reduced bioreactor volumes, secondary settling tank surface area and oxygen demand. Further, the ENBNRAS system provides opportunity for substantial system intensification. The performance and characterization of the ENBNRAS system has been successfully demonstrated at lab-scale (Hu et al., 2000, Sötemann et al., 2002), but has not yet been tested in full-scale implementation. In collaboration between the City of Tshwane Metropolitan Municipality (CTMM) and the University of Cape Town, ENBNR activated sludge is being implemented at fullscale at the Daspoort Waste Water Treatment Works (DWWTW) in Central Pretoria, South Africa. This paper describes the preliminary design of this full-scale plant and initial implementation.
\end{abstract}

\section{Introduction}

In the external nitrification (EN) biological nutrient removal (BNR) activated sludge (AS) system, the nitrification process is removed from the main BNRAS system to a fixed media system external to the AS system (Hu et al., 2003). This resolves the two main constraints of conventional BNRAS systems, i.e. the long sludge age requirement for nitrification and the difficulty in achieving near complete nitrogen removal. Specifically, the sludge age of the system can successfully be reduced from typically 20-25 days in conventional BNRAS systems to 8-10 days in the ENBNRAS system, resulting in a 30\% reduction in the activated sludge system volume required (Hu et al., 2000). Additionally, the aerobic mass fraction can be reduced from $50-60 \%$, to less than $30 \%$ in the ENBNRAS system, and, concomitantly, the anoxic mass fraction can be increased from 25-35\% to 55\% (anaerobic mass fraction of $15 \%)$. The increase in anoxic mass fraction, together with the fact that nitrification precedes denitrification in the system layout, enables the possibility of near complete denitrification. Moving nitrification to the fixed media system and the increased denitrification significantly reduce (by $2 / 3$ rds) the oxygen requirements in the ENBNRAS system compared to the conventional BNRAS system. Further, the ENBNRAS system requires significantly reduced secondary settling tank surface area due to likely amelioration of anoxic-aerobic (AA, or low F/M) filamentous bulking (Casey et al., 1994). Thus, the ENBNRAS system provides opportunity for substantial system intensification. The performance and characterization of the ENBNRAS system has been

This paper was originally presented at the 2004 Water Institute of South Africa (WISA) Biennial Conference, Cape Town, South Africa, 2-6 May 2004.

* To whom all correspondence should be addressed.

喵+2721 650-2583.; fax: +2721 689-7471;

e-mail: markw@eng.uct.ac.za successfully demonstrated at lab-scale (Hu et al., 2000, Sötemann et al., 2002), but has not yet been tested in full-scale implementation. In collaboration between the City of Tshwane Metropolitan Municipality (CTMM) and the University of Cape Town, ENBNR activated sludge is being implemented at full-scale at the Daspoort Waste Water Treatment Works (DWWTW) in Central Pretoria, South Africa.

This paper describes the design and initial implementation of full-scale external nitrification biological nutrient removal(ENBNR) activated sludge at the Daspoort Waste Water Treatment Works (DWWTW) operated by the City of Tshwane Metropolitan Municipality (CTMM) in Central Pretoria, South Africa. It presents a general description of the DWWTW, an overview of the main elements in the initial evaluation of DWWTW as a candidate site for EN implementation, and a summary of current performance of the EN system at DWWTW.

\section{Daspoort Waste Water Treatment Works plant description}

A detailed description of the Daspoort Waste Water Treatment Works (DWWTW) prior to implementation of the ENBNR activated sludge system is presented by $\mathrm{WMB}$ and Bigen Africa (2000). In brief, the DWWTW is located on the southern banks of the Apies River on the north-western edge of the Pretoria Central Business District (CBD). Wastewater from the Central Pretoria area is collected in a main outfall sewer that runs alongside the Apies River past the DWWTW to the Rooiwal Waste Water Treatment Works (RWWTW). The DWWTW abstracts raw wastewater from this outfall sewer at two points, to be treated in its older "Eastern” Works, and newer "Western” Works respectively. The influent flows drawn from both locations are controlled by automatic sluice gates maintaining an approximately constant influent flowrate to DWWTW.

The influent wastewater to both Works at DWWTW undergo mechanical screening, grit removal and primary settling in Dort- 
TABLE 1

Summary of the main secondary unit processes at Daspoort Waste Water Treatment Works

\begin{tabular}{|l|l|c|c|c|}
\hline Module & Type of Unit Process & Quantity & $\begin{array}{c}\text { Constructed, } \\
\text { Upgraded }\end{array}$ & $\begin{array}{c}\text { Capacity } \\
\text { (Ml/d) }\end{array}$ \\
\hline $1-4$ & Single bed rock media trickling filters & 16 & $1913-1920$ & 9 \\
$5-6$ & Dual bed rock media trickling filters & 4 & 1945,1995 & 9 \\
$9-11$ & 3-Stage Bardenpho BNR activated sludge systems & 3 & 1975,1988 & 40 \\
\hline
\end{tabular}

mund-type vertical flow settling tanks. The Eastern Works is a trickling filter (TF) plant situated upstream of the Western Works, which is a conventional BNRAS system. The Eastern Works comprises 2 sets of TF systems, Modules 1-4 and 5-6 respectively, while the Western Works comprises BNRAS systems Modules 9-11 (Modules 7-8 were decommissioned in 1985 due to structural failure and demolished in 1996). The essential features of these systems are summarised in Table 1.

\section{Design evaluation of Daspoort Waste Water Treatment Works}

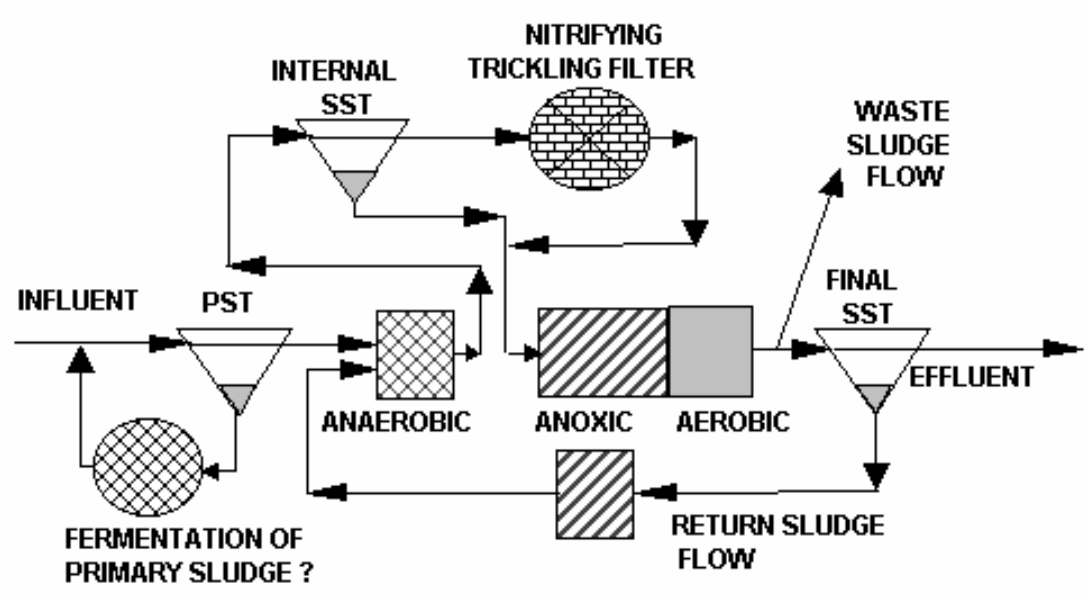

The initial design to evaluate DWWTW for full-scale implementation of ENBNR is contained in detail in Muller et al. (2003), and is summarised here.

\section{Available infrastructure at the Daspoort Waste Water Treatment Works}

The general design approach was to integrate the Eastern Works' trickling filter (TF) Modules 5-6 with the Western Works' Module 9 BNRAS system. Available infrastructure was as follows:

The Western Works had 6 Dortmund-type primary settling tanks (PST's) that provided a common settled sewage to three parallel BNRAS systems - Modules 9, 10 and 11. Each Module was made up of a series of 9 basins (or compartments) of $750 \mathrm{~m}^{3}$ each, for a total process volume of $6750 \mathrm{~m}^{3}$ for each module. The modules were operated in a 3-stage Bardenpho configuration: sequentially, the first 2 compartments were anaerobic $\left(1500 \mathrm{~m}^{3}\right)$, the next three anoxic $\left(2250 \mathrm{~m}^{3}\right)$ and the last four aerobic $\left(3000 \mathrm{~m}^{3}\right)$. Settled influent entered the first anaerobic compartment, as did the return activated sludge (RAS) from the secondary settling tanks (SSTs). Nitrate rich mixed liquor was recycled from the last aerobic compartment to the first anoxic compartment (called the "arecycle"). Unaerated compartments were each fitted with two mixers, and each aerobic compartment with 1 x $45 \mathrm{~kW}$ surface aerator. Ultimately, the mixed-liquor (ML) in each module overflowed an effluent weir in the last compartment enroute to 2 cylindrical (11.6 m diameter) SSTs per module for final clarification. The sludge age in each module was controlled hydraulically, by wasting directly from the last compartment (aerobic).

In the Eastern Works system, Modules 5-6 comprise 2 pairs of dual bed rock media TFs of $25.9 \mathrm{~m}$ diameter and $3.66 \mathrm{~m}$ height each, for a total system volume of $7714 \mathrm{~m}^{3}$ (1928 $\mathrm{m}^{3}$ per TF). The specific surface area of the rock media is rated at $45 \mathrm{~m}^{2} / \mathrm{m}^{3}$, which gave a total specific surface area of roughly $347000 \mathrm{~m}^{2}$ for the TF system.

Figure 1

The external nitrification (EN) biological nutrient removal (BNR) activated sludge system process flow diagram

\section{Design concept}

The general concept was to integrate the Eastern Works' Modules 5-6 TFs with the Western Works' BNRAS Module 9 in the ENBNRAS configuration, Fig. 1 (Hu et al., 2000).

This integrated design required provision of internal settling tanks (ISTs) between the anaerobic and anoxic reactors. In the design, 4 of the original 6 Dortmund PST's were modified to serve as ISTs for the EN configuration while the remaining 2 were retained for primary settling, to provide a common settled sewage to the three parallel AS Modules.

The 9 activated sludge compartments of Module 9 would be modified to give the following configuration (Fig. 2): Compartment 1 partitioned into pre-anoxic and anaerobic (1/3 to 2/3 respectively) zones; Compartments 2 and 3 anaerobic; Compartments 4, 5 and 6 primary anoxic; and Compartments 7, 8 and 9 aerobic, with Compartment 7 to be switched to primary anoxic later in operation. With Compartment 7 aerobic, this configuration would give mass fractions of pre-anoxic $=10 \%$, anaerobic $=28 \%$, primary anoxic $=31 \%$ and aerobic $=31 \%$; whereas, with Compartment 7 anoxic, mass fractions of primary anoxic $=41 \%$ and aerobic $=21 \%$. This latter mass fraction distribution is the one recommended from the laboratory-scale investigations (Hu et al., 2000). The settled sewage would enter Module 9 at the first anaerobic compartment (second 2/3rds of Compartment 1, see Fig. 2). Mixed liquor would be pumped from the last anaerobic compartment (Compartment 3 ) to the 4 Dortmund type ISTs. The underflow from the ISTs would be pumped to the first primary anoxic compartment (Compartment 4). The overflow from the ISTs would be pumped to Modules 5-6 TFs, and the nitrified TFs effluent collected and 


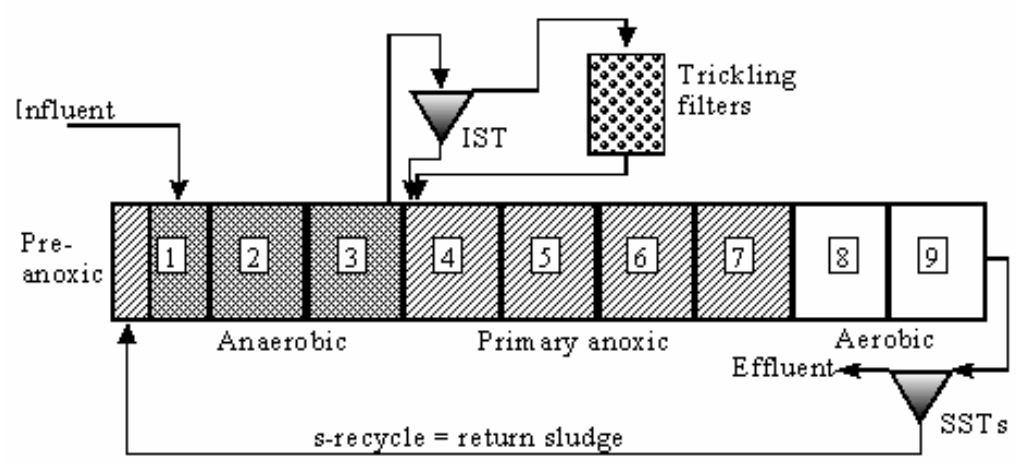

Figure 2

Proposed configuration for ENBNR activated sludge system at Daspoort Waste Water Treatment Works (DWWTW), with Compartment 7 anoxic

TABLE 2

Average characteristics of settled sewage influent at Daspoort Waste Water Treatment Works (January 2000 - April 2002) used in the design evaluation (*Indicates assumed value)

\begin{tabular}{|l|c|c|c|}
\hline Settled sewage influent parameter & Symbol & Value & Unit \\
\hline Influent flowrate & $\mathrm{Q}_{\mathrm{i}}$ & 14 & $\mathrm{M} \ell / \mathrm{d}$ \\
COD concentration & $\mathrm{S}_{\mathrm{ti}}$ & 320 & $\mathrm{mgCOD} / \ell$ \\
Unbiodegradable particulate fraction & $\mathrm{f}_{\text {up }}$ & $0.04^{*}$ & $\mathrm{COD} / \mathrm{COD}$ \\
Unbiodegradable soluble fraction & $\mathrm{f}_{\mathrm{us}}$ & $0.10^{*}$ & $\mathrm{COD} / \mathrm{COD}$ \\
TKN concentration & $\mathrm{N}_{\mathrm{ti}}$ & 35.8 & $\mathrm{mgN} / \ell$ \\
Ammonia concentration & $\mathrm{N}_{\mathrm{ai}}$ & 19.5 & $\mathrm{mgN} / \ell$ \\
Nitrate concentration & $\mathrm{NO}_{3}$ & 0.0 & $\mathrm{mgN} / \ell$ \\
Ortho-P concentration & $\mathrm{PO}_{4}$ & 4.5 & $\mathrm{mgP} / \ell$ \\
Total-P concentration & $\mathrm{P}_{\mathrm{ti}}$ & 5.8 & $\mathrm{mgP} / \ell$ \\
& & & \\
\hline
\end{tabular}

TABLE 3

Activated sludge characteristics for Daspoort Waste Water Treatment Works used in the preliminary design evaluation

\begin{tabular}{|l|c|c|c|}
\hline Activated sludge characteristic & Symbol & Value & Unit \\
\hline Sludge age & $\mathrm{R}_{\mathrm{s}}$ & 11 & $\mathrm{~d}$ \\
Measured MLSS concentration & $\mathrm{X}_{\mathrm{t,m}}$ & 3.5 & $\mathrm{gTSS} / \ell$ \\
Mass of MLSS in Module 9 & $\mathrm{MX}_{\mathrm{t}, \mathrm{m}}$ & 24000 & $\mathrm{kgTSS}$ \\
MLVSS/MLSS ratio & $\mathrm{f}_{\mathrm{i}}$ & 0.85 & $\mathrm{VSS} / \mathrm{TSS}$ \\
Dilute sludge volume index & $\mathrm{DSVI}$ & 160 & $\mathrm{~m} \ell / \mathrm{g}$ \\
\hline
\end{tabular}

returned to the first primary anoxic compartment (Compartment 4). The mixed liquor from the last aerobic compartment (Compartment 9) would overflow a weir to the 2 existing SSTs. The RAS (underflow) from the SSTs would be discharged to the pre-anoxic compartment (first 1/3 of Compartment 1).

\section{Influent wastewater and activated sludge characteristics}

As described above, the BNRAS system of Module 9 would receive settled sewage from vertical flow Dortmund primary settling tanks (PSTs). The average settled sewage characteristics for the period January 2000 - April 2002 were used in the design evaluation, with assumed values of 0.10 and 0.04 for the unbiodegradable soluble and particulate COD fractions respectively, and are summarised in Table 2. The average values for the process characteristics for the BNRAS system used in the design were obtained by direct measurement, theoretical estimation and reasonable assumption. As a check, the measured mixed-liquor (ML) total suspended solids (TSS) concentration in the system was compared with that predicted by the Steady-State theory of Marais and Ekama (1976). The predicted mass of mixed-liquor suspended solids (MLSS) in the system (9 $600 \mathrm{kgTSS}$ ) was substantially less than that measured (24 $000 \mathrm{kgTSS}$, at $3.5 \mathrm{gTSS} / \ell$ ), which introduced significant uncertainty to subsequent determinations. To be conservative, it was decided to use the measured MLSS value of $3.5 \mathrm{gTSS} / \ell$ in the design (this concentration is used to determine the surface areas of the ISTs and SSTs, see below). The design values used are summarised in Table 3.

\section{Process design}

The process design for EN implementation was based on the DWWTW system characteristics described above. The key points in the design are summarised below, for details see Muller et al. (2003).

\section{Selection of influent and RAS recycle flowrates}

The design evaluation estimated the capacity of the nitrifying trickling filters (NTFs) of Modules 5-6 to be approximately $347 \mathrm{kgN} / \mathrm{d}$ assuming a conservative nitrification rate of $1 \mathrm{gN} / \mathrm{m}^{2} / \mathrm{d}$ for the rock media NTFs (media volume of $7714 \mathrm{~m}^{3}$ at $45 \mathrm{~m}^{2} / \mathrm{m}^{3}$ surface area). However, the expected influent free-and-saline-ammonia (FSA) load to be nitrified on the NTFs is approximately 406 $\mathrm{kgN} / \mathrm{d}$ at an influent flow rate of $14 \mathrm{M} \ell / \mathrm{d}$. Hence, it was recommended that the maximum influent flowrate for the design be reduced to $10 \mathrm{M} \ell / \mathrm{d}$; this gave FSA and TKN loads on the TFs less than their capacity. This determination corresponds with a RAS recycle ratio $(R)$ of $0.5: 1$ with respect to the plant influent flow $\left(Q_{i}\right)$, which was set at a low value to minimise the hydraulic load on the ISTs, see below.

\section{Evaluation of internal settling tank (IST) capacity}

The design evaluation determined that the modified Dortmund ISTs would be the hydraulic bottleneck in the system. Each Dortmund tank measures $13 \mathrm{~m}$ in diameter at its weir elevation, and is equipped with a $2 \mathrm{~m}$ diameter vertical inlet pipe located in its centre. The tank diameter at the bottom of the inlet pipe is estimated at approximately $9 \mathrm{~m}$. This gives respective net overflow surface areas of 129.5 and $60.5 \mathrm{~m}^{2}$ at the weir and inlet pipe discharge elevations respectively for each tank, corresponding to total system IST surface areas of 518 and $242 \mathrm{~m}^{2}$ respectively. By adjusting the measured MLSS concentration of $3.5 \mathrm{gTSS} / \ell$ to $2.5 \mathrm{gTSS} / \ell$ to take account of the reduced influent flow of $10 \mathrm{M} \ell / \mathrm{d}$ for the design, the theoretical relationships of Ekama et al. (1997) and Ekama and Marais (1986) were applied to estimate sludge settling velocities and maximum overflow rates allowable in the ISTs. On this basis the design determined that for the measured sludge DSVI of 160 $\mathrm{m} \ell / \mathrm{g}$, and designed influent and RAS flowrates of 10 and $5 \mathrm{M \ell} / \mathrm{d}$, 
respectively, the IST would fail at an MLSS concentration of 3.5 gTSS/ $/$ and be maximally loaded for an MLSS concentration of 2.5 gTSS/ $\ell$ (at 3.5 and 2.5 gTSS/ $/$, predicted sludge settling velocities $\left(\mathrm{V}_{\mathrm{s}}\right)$ for a DSVI of $160 \mathrm{~m} \ell / \mathrm{g}$ are 1.1 and $1.8 \mathrm{~m} /$ $\mathrm{h}$ respectively). For $15 \mathrm{M} \ell / \mathrm{d}$ inflow to the ISTs (influent of $10 \mathrm{Ml} / \mathrm{d}+$ RAS of $5 \mathrm{M \ell} / \mathrm{d}$ ), and underflow and overflow rates of 3 and $12 \mathrm{M \ell} / \mathrm{d}$ respectively, the overflow rate is 2.1 $\mathrm{m} / \mathrm{h}$ at the inlet pipe discharge (surface area of $242 \mathrm{~m}^{2}$ ), and $1.0 \mathrm{~m} / \mathrm{h}$ at the weir elevation (surface area of $518 \mathrm{~m}^{2}$ ) of the ISTs. Clearly, using the smaller surface area at the inlet pipe discharge would cause the ISTs to fail for these conditions. Thus, it was recommended that the inlet pipes

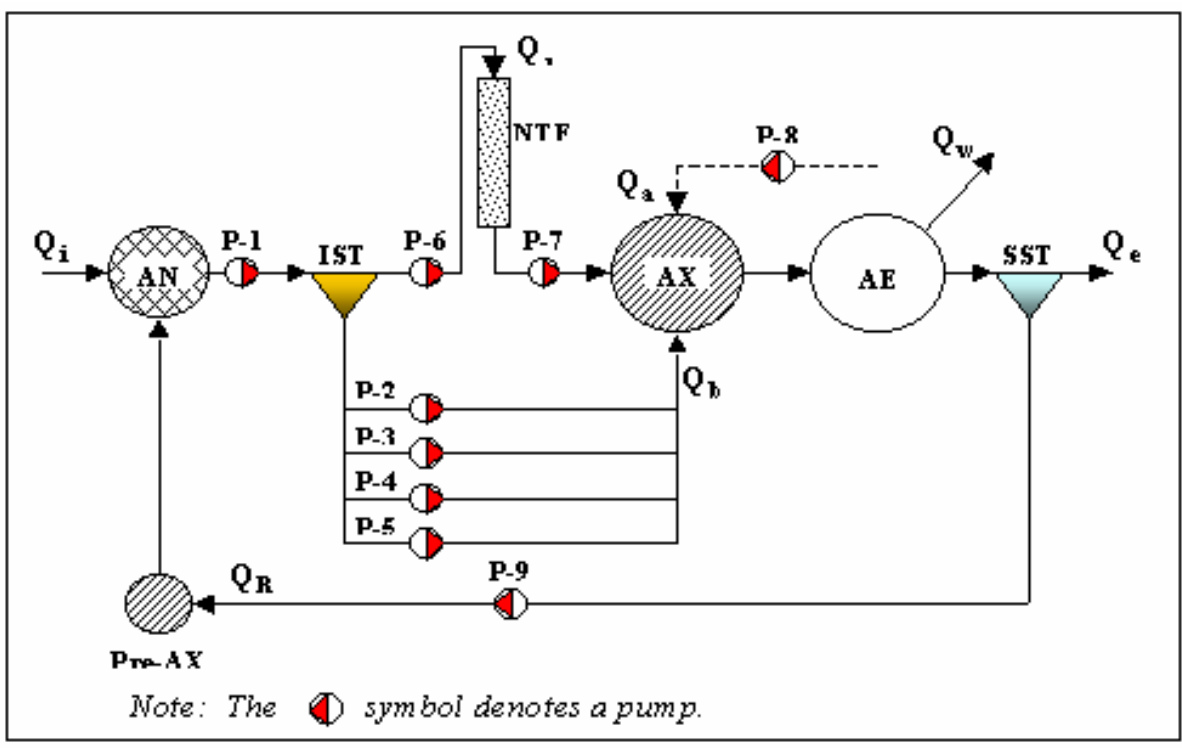
to the Dortmund tanks be cut at the weir elevation (to maximise the available overflow surface area), or alternatively be sealed at the bottom with feed slots cut into the side of the inlet pipe at the weir level - this would significantly increase the surface area of the ISTs and give safe operation.

\section{Final secondary settling tanks (SSTS)}

The available SST surface area for Module 9 was $212 \mathrm{~m}^{2}$. This gave an overflow rate of $1.9 \mathrm{~m} / \mathrm{h}$ at an influent flow rate of $10 \mathrm{Ml} / \mathrm{d}$. For this overflow rate, with flux load capacity at $75 \%$ of the flux theory (Ekama et al., 1997) the DSVI must be $<140 \mathrm{~m} \ell / \mathrm{g}$. However, the average DSVI measured was $160 \mathrm{~m} \ell / \mathrm{g}$. This implies that the DSVI must improve to prevent failure of the SSTs. A significant improvement in DSVI can be expected with implementation of ENBNRAS, due to the low aerobic mass fraction (Hu et al., 2000). Thus, the available SST surface area was considered to be adequate.

\section{Aeration capacity}

For the available aeration capacity (2x45 kW in Compartments 8 and 9), the highest influent COD concentration that can be treated is $500 \mathrm{mgCOD} / \ell$. Since the measured settled sewage COD concentration is significantly less, at $320 \mathrm{mgCOD} / \ell$, the available aeration capacity was adequate.

\section{Determination of the pre-anoxic reactor volume}

Determination of the pre-anoxic volume was prepared subsequent to the initial design, see Muller et al. (2003). Based on average MLSS and estimated RAS recycle rates, it was recommended that the pre-anoxic reactor volume be $1 / 3$ of Compartment 1 , or approx. $250 \mathrm{~m}^{3}$, with the balance of Compartment 1 as anaerobic (Fig. 2).

\section{Summary of design recommendations for the full- scale implementation of EN}

In summary, the design evaluation recommended the following for implementation of ENBNRAS at DWWTW:

- Reduce the influent flow $\left(\mathrm{Q}_{\mathrm{i}}\right)$ to $10 \mathrm{M \ell} / \mathrm{d}$ (with a RAS rate of $5 \mathrm{M} \ell / \mathrm{d})$

- Introduce the mixed-liquor into the ISTs at or near the weir elevation (to maximise the available overflow surface area)

- Operate the BNRAS system with a sludge age $\left(\mathrm{R}_{\mathrm{s}}\right)$ of approximately 11 days

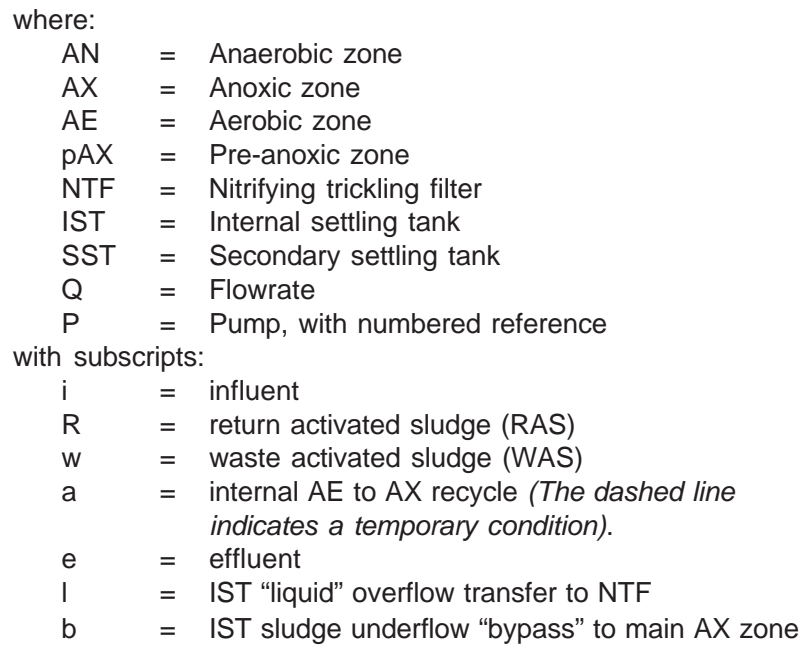

Figure 3

Schematic diagram of the external nitrification (EN) system implemented at Daspoort Waste Water Treatment Works

(DWWTW)

- Maintain a system mixed-liquor suspended solids (MLSS) concentration of approximately $2.5 \mathrm{~g} / \ell$; the expected MLSS is much lower, at about $1.5 \mathrm{~g} / \ell$

- Maintain the DSVI $\leq 140 \mathrm{~m} \ell / \mathrm{g}$.

\section{Implementation of external nitrification at DWWTW}

\section{Layout of the DWWTW external nitrification system}

Retrofitting of Modules 5-6 and 9, and installation of new equipment at DWWTW, began in late 2002 and was sufficiently completed by 18 August 2003 for the ENBNRAS activated sludge system to be placed in-service. A process diagram of the ENBNRAS system as implemented at DWWTW is shown in Fig. 3; Fig. 3 shows newly purchased and installed pumps (P1 - P7) as well as existing a-recycle and RAS pumps (P8 and P9 respectively). The rated capacities and applicable flow streams of the new pumps are listed in Table 4. 
TABLE 4

Capacities and flow streams of the new pumps installed in the external nitrification system at Daspoort Waste Water Treatment Works

\begin{tabular}{|c|c|c|c|c|}
\hline Pump(s) & Flow Stream & $\begin{array}{l}\text { Design } \\
\text { l/s (Ml/d) }\end{array}$ & $\begin{array}{l}\text { Installed } \\
\text { l/s (Ml/d) }\end{array}$ & $\begin{array}{c}\text { Actual } \\
\text { l/s (M/ld) }\end{array}$ \\
\hline P1 & ML from AN zone to IST & $175(15)$ & $175(15)$ & $120(10)$ \\
\hline P2-P5 & IST underflow bypass to AX & $60(5)$ & $60(5)$ & $40(3.5)$ \\
\hline P6 & IST liquid overflow to NTF & $120(10)$ & $175(15)$ & N/A \\
\hline P7 & NTF effluent to AX & $120(10)$ & $175(15)$ & N/A \\
\hline
\end{tabular}

Daspoort WCW Solids Trends June - December 2003

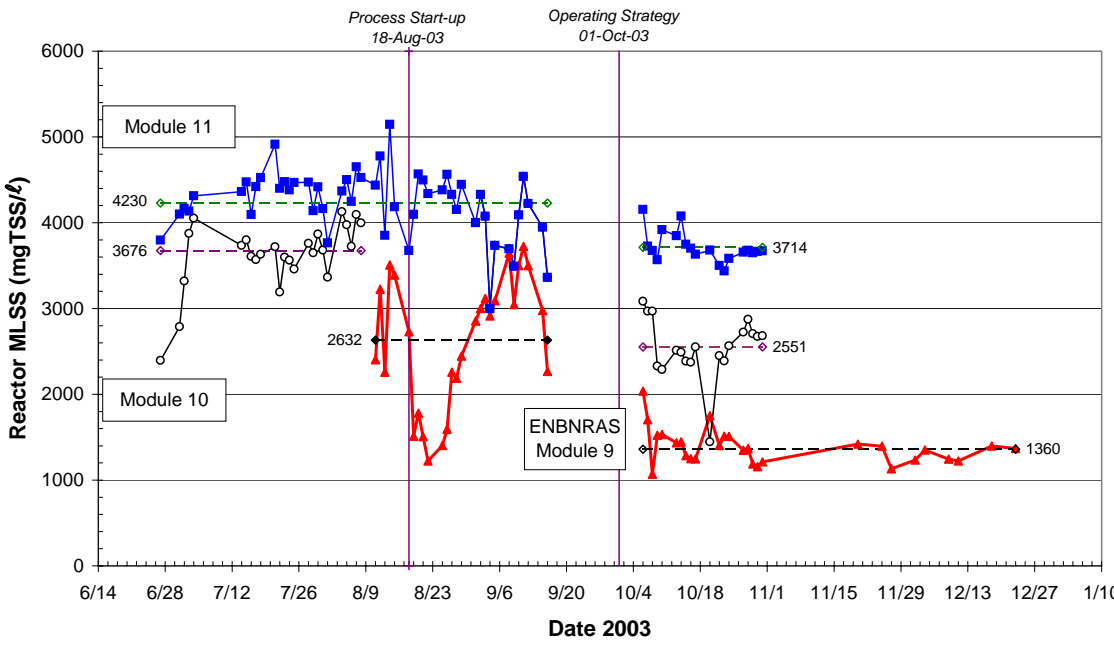

Figure 4

Mixed-liquor suspended solids (MLSS) trends at Daspoort Waste Water Treatment Works (DWWTW) for June -

December 2003

\section{Start-up of the external nitrification system at DWWTW}

Operation of the ENBNRAS system at Daspoort was initiated on $18^{\text {th }}$ August 2003. Operational and sampling strategies for start-up were finalised in October and are contained in Muller et al. (2003). A conservative approach was adopted in the start-up strategies to account for operational constraints within the system and limited staff availability. In brief, the start-up period was defined as the transition from the original (conventional) BNRAS operating mode to the final ENBNRAS system configuration. It was recommended to achieve the ultimate (design) ENBNRAS configuration in the three phased approach summarised below:

\section{Phase I: Transfer of nitrification from the activated sludge process to the nitrifying trickling filters (NTFs)}

The main goal in Phase I of the start-up period is the effective transfer of complete nitrification from the suspended media activated sludge aerobic (AE) zone to the fixed media nitrifying trickling filters (NTFs): In the configuration prior to ENBNRAS implementation, namely the 3-stage Bardenpho, nitrification would have occurred in the aerobic zone of the system since nitrifiers were supported in this system (larger aerobic mass fraction and longer sludge age); for successful implementation of ENBNR, this nitrification needs to virtually completely transferred to the NTFs.
Before nitrification transference takes place, (i) the nitrate load to the main anoxic reactor will be inadequate, (ii) nitrification in the main aerobic reactor will cause high nitrate loads to the pre-anoxic reactor, which may exceed this reactor's denitrification potential and cause nitrate to enter the anaerobic reactor, to the detriment of $\mathrm{P}$ removal, and (iii) if nitrification is lost in the AS part of the system before it establishes in the NTFs, the effluent ammonia concentrations will be unacceptably high. During the transition from AS to NTF nitrification, it is recommended that the a-recycle from the aerobic to anoxic zones be retained, to maintain a nitrate load to the primary anoxic reactor.

The essential criteria to determine if Phase I has been successfully achieved, is a NTF effluent ammonia concentration consistently $<3 \mathrm{mgN} / \ell$, with the Phase I $\mathrm{N}$ load to the NTFs $\left(Q_{\mathrm{i}}=5 \mathrm{M \ell} / \mathrm{d}\right.$, RAS rate $=5 \mathrm{M \ell} / \mathrm{d}$, IST overflow rate $=7.5 \mathrm{M} \ell / \mathrm{d}$ and IST bypass rate $=2.5 \mathrm{M} \ell / \mathrm{d}$ ). With the achievement of this goal, the a-recycle can be removed and aeration in Compartment 7 stopped.

\section{Phase II: Achieve successful sludge} settleability in the EN system

The main goal in Phase II is to achieve good sludge settleability in the BNRAS part of the system. Good sludge settleability is essential for successful operation of the ISTs. The essential criteria to assess completion of Phase II is a consistent DSVI $<100 \mathrm{~m} \ell / \mathrm{g}$. With this goal achieved, the load to the system can be increased to the design $10 \mathrm{M} \ell / \mathrm{d}_{(\mathrm{i}}=10$ $\mathrm{M} \ell / \mathrm{d}$, RAS rate $=5 \mathrm{M} \ell / \mathrm{d}$, IST overflow rate $=11.25 \mathrm{M \ell} / \mathrm{d}$ and IST bypass rate $=3.75 \mathrm{M \ell} / \mathrm{d}$ ).

\section{Phase III: Implement the final design configuration for the EN system at DWWTW}

The main goal in Phase III is to implement the ultimate (final) design conditions (i.e. design loadings, recycle rates etc.) for the EN system at DWWTW. The essential criteria to assess attainment of Phase III is consistent overall system performance (i.e. stable TSS, VSS, DSVI, effluent values etc.).

\section{Current performance of the external nitrification system}

Operation of the ENBNRAS system at DWWTW is currently in the start-up phases. Since system initiation in August, numerous equipment failures and process disruptions have occurred which required various operational interventions to safeguard overall performance of the plant. By necessity, these operational changes were implemented frequently and often simultaneously, making systematic evaluation of resultant effects difficult. Despite this uncertainty, the following data is presented as a basic indication of current ENBNRAS system performance at DWWTW.

\section{Mixed-liquor suspended solids (MLSS) trend}

The concentration of mixed-liquor suspended solids (MLSS) in the parallel activated sludge Modules 9, 10 and 11 for June - December 2003 are shown in Fig. 4. 
Daspoort WCW DSVI Trends for October - December 2003

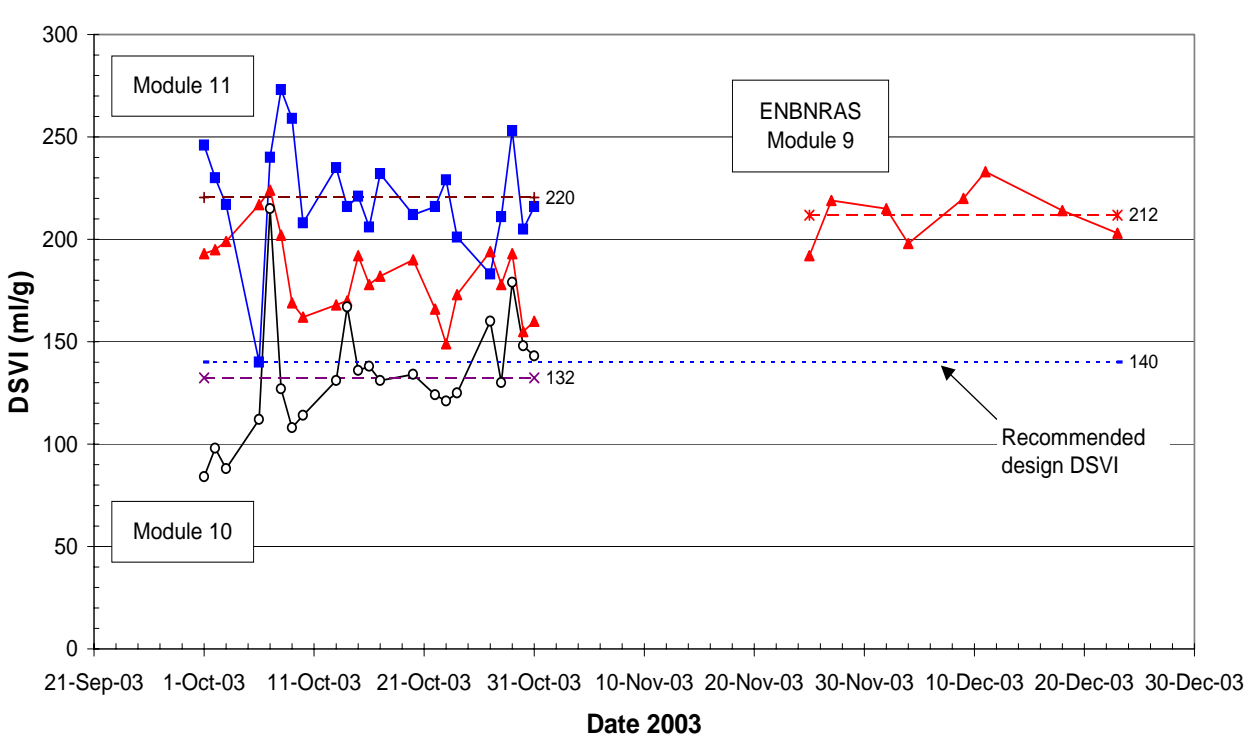

Figure 5

Dilute sludge volume index (DSVI) trends fro Modules 9, 10 and 11 at Daspoort Waste Water Treatment Works (DWWTW) for October - December 2003

TABLE 5

Average settled and NTF influent wastewater values for 19 November 23 December 2003 (AVG = average; SSD = sample standard deviation; $\mathrm{N}=$ number of data)

\begin{tabular}{|l|c|c|c|c|c|c|c|}
\hline \multirow{2}{*}{$\begin{array}{l}\text { Para- } \\
\text { meter }\end{array}$} & \multirow{2}{*}{ Unit } & \multicolumn{3}{|c|}{ Settled wastewater } & \multicolumn{3}{c|}{ NTF Influent } \\
\cline { 3 - 8 } & & AVG & SSD & N & AVG & SSD & N \\
\hline pH & - & 7.42 & 0.06 & 9 & 7.15 & 0.07 & 6 \\
Temp. & ${ }^{\circ} \mathrm{C}$ & 25.3 & 0.9 & 9 & 24.5 & 0.4 & 6 \\
$\mathrm{COD}$ & $\mathrm{mgCOD} / \ell$ & 281 & 29 & 8 & 45 & 9 & 6 \\
$\mathrm{TKN}$ & $\mathrm{mgN} / \ell$ & 39.5 & 4.8 & 9 & 8.26 & 2.05 & 6 \\
TSS & $\mathrm{mgTSS} / \ell$ & - & - & - & 12.5 & 5.6 & 6 \\
FSA & $\mathrm{mgN} / \ell$ & 34.0 & 2.5 & 9 & 6.3 & 2.28 & 6 \\
\hline
\end{tabular}

\begin{tabular}{|c|c|c|c|c|}
\hline \multicolumn{5}{|c|}{$\begin{array}{c}\text { TABLE } 6 \\
\text { Average NTF effluent values for Module } 5 \text { for } \\
\text { December } 9-23,2003 \text { (AVG = average; } \\
\text { SSD = sample standard deviation; } \\
\mathrm{N}=\text { number of data) }\end{array}$} \\
\hline \multirow{2}{*}{$\begin{array}{l}\text { Para- } \\
\text { meter }\end{array}$} & \multirow[t]{2}{*}{ Unit } & \multicolumn{3}{|c|}{ NTF effluent } \\
\hline & & AVG & SSD & $N$ \\
\hline $\mathrm{pH}$ & - & 8.06 & 0.2 & 6 \\
\hline Temp. & ${ }^{\circ} \mathrm{C}$ & 23.8 & 0.6 & 6 \\
\hline COD & $\mathrm{mgCOD} / \ell$ & 24 & 4 & 6 \\
\hline TKN & $\mathrm{mgN} / \ell$ & 2.52 & 1.21 & 6 \\
\hline TSS & $\operatorname{mgTSS} / \ell$ & 12.3 & 6.1 & 6 \\
\hline FSA & $\mathrm{mgN} / \ell$ & 0.19 & 0.15 & 6 \\
\hline $\mathrm{NO}_{3}$ & $\mathrm{mgN} / \mathrm{l}$ & 9.88 & 4.88 & 6 \\
\hline $\mathrm{NO}_{2}^{3}$ & $\mathrm{mgN} / \ell$ & 8.67 & 3.88 & 6 \\
\hline
\end{tabular}

From Fig. 4, the MLSS in Module 9 has varied widely since August, but appears to have stabilised at $1360 \mathrm{mgTSS} / \ell$ since early November. This is significantly less than the recommended operating MLSS of $2500 \mathrm{mgTSS} / \ell$, but close to the theoretically expected value of $1500 \mathrm{mgTSS} / \ell$, which indicates reasonable control of sludge age - (see Summary of Design Recommendations for the Full-Scale Implementation of EN above).

\section{Sludge settleability}

As a measure of sludge settleability, the diluted sludge volume index (DSVI) of the parallel activated sludge Modules 9, 10 and 11 for October 2003 are shown in Fig. 5.

The mixed-liquor DSVI in Module 9 averaged $182 \mathrm{~m} \ell / \mathrm{gTSS}$ for October 2003 and is currently $212 \mathrm{~m} \ell / g T S S$ (November - December 2003). This is significantly higher than the $140 \mathrm{~m} \ell / \mathrm{gTSS}$ recommended in the design evaluation, and is similar to the October average for Module 11 (200 m $/ \mathrm{g})$. Until significant reduction in DSVI is achieved, Phase II goals cannot be met and Phase III implemented.

\section{Nitrification performance of the nitrifying trickling filters (NTFs)}

A summary of average settled sewage and NTF influent wastewater for the period 19 November to 23 December 2003 is presented in Table 5. Each day's values were evaluated within the data set $95 \%$ confidence interval, with those lying outside this interval ( $\approx$ mean $\pm 1.96 *$ sample standard deviation) rejected as outliers. As mentioned previously, however, several equipment failures and process disruptions occurred since system initiation in August. To establish consistency in system operation, the following operational changes were implemented in December: the influent flow to the ENBNRAS system was reduced from 10 to $5 \mathrm{M \ell} / \mathrm{d}$, the arecycle between the aerobic and primary anoxic reactors was reactivated, and the number of in-service downstream process units were reduced by half - i.e. the ISTs from 4 to 2, the SSTs from 2 to 1 and the NTFs from 4 to 2. Since the influent to the NTFs are directly impacted by these changes, only NTF influent data after these changes (December $9-23,2003$ ) are included in Table 5. It should be noted, therefore, that consequently the data set is still small and thus insufficient for more detailed analysis.

NTF effluent values are similarly few, but are presented in Table 6. Furthermore, as mentioned earlier, one NTF Module (Module 6) was placed out-of-service in December, thus the average NTF effluent values in Table 6 are for Module 5 only.

On average, therefore, approximately $97 \%$ of influent freeand-saline ammonia (FSA) to Module 5 is nitrified. This translates 
into roughly $42.2 \mathrm{kgN} / \mathrm{d}$ for an average influent flow of approximately $6.9 \mathrm{M \ell} / \mathrm{d}$ to Module 5, which gives an apparent surface specific nitrification rate of about $0.24 \mathrm{gN} / \mathrm{m}^{2} / \mathrm{d}$ (or volumetric nitrification rate of $10.9 \mathrm{gN} / \mathrm{m}^{3}$ ) for the 2 rock media trickling filters of Module 5. The corresponding wetting rate is about $0.746 \mathrm{~m} / \mathrm{h}$ on average. Unfortunately no similar applications (optimised for nitrification only) of rock media trickling filters were found in the literature for comparison. However, although not directly comparable due to higher oxygen transfer rates and subject to different operating conditions (e.g. temperature, hydraulic loading rate, extent of media predation), several plastic media trickling filters in tertiary treatment applications were found, which suggest apparent surface specific nitrification rates of 0.39 (Boller and Gujer, 1986), 1.24 (Parker et al., 1989) and 1.6 (Parker et al., 1995) gN/m²/d among others. It would appear, therefore, that, while the DWWTW Module 5 NTFs are nitrifying successfully ( $97 \%$ FSA removal), the rate of nitrification per $\mathrm{m}^{2}$ of surface area is still relatively low, probably due to the recent startup. This will be monitored during future research and updated in the conference presentation.

\section{Conclusion}

In conclusion, the initial design evaluation for implementing ENBNRAS at DWWTW recommended:

- Reduce the influent flow $\left(\mathrm{Q}_{\mathrm{i}}\right)$ to $10 \mathrm{M} \ell / \mathrm{d}$ (with a return sludge rate of $5 \mathrm{M} \ell / \mathrm{d}$ )

- Introduce the mixed-liquor into the ISTs at or near the weir elevation (to maximise the available overflow surface area)

- Operate the BNRAS system with a sludge age $\left(\mathrm{R}_{\mathrm{s}}\right)$ of approximately 11 days

- Maintain a system mixed-liquor concentration (X) of approximately $2.5 \mathrm{~g} / \ell$

- $\quad$ Try to keep the DSVI $\leq 140 \mathrm{~m} \ell / \mathrm{g}$.

The ENBNRAS system at DWWTW was started-up on the $18^{\text {th }}$ August 2003. Operating and sampling strategies for the start-up period were prepared and distributed in October. Since process initiation, numerous equipment failures and operational interventions resulted in unquantifiable effects to the process. Additionally, the lack of sufficient data at the present time prevents characterisation of the system behaviour and interpretation of the system performance with confidence. However, despite high DSVI values in the ENBNRAS system currently, preliminary results for the rock media TFs indicate the successful onset of nitrification (97\% ammonia removal efficiency) although the apparent surface specific nitrification rate is still relatively low $\left(0.24 \mathrm{gN} / \mathrm{m}^{2} / \mathrm{d}\right)$.

\section{Acknowledgements}

This research was supported by the Water Research Commission, Water Sanitation Services South Africa, a subsiduary of Ondeo Services, the Department of Trade and Industry through its Technology and Human Resources in Industry Programme (THRIP), the National Research Foundation and the University of Cape Town, and is published with their permission.

\section{References}

BOLLER M and GUJER W (1986) Nitrification in tertiary trickling filters followed by deep-bed filters. Water Res. 20 (11) 1363-1373.

CASEY TG, WENTZEL MC, EKAMA GA, LOEWENTHAL RE and MARAIS GvR (1994) An hypothesis for the cause and control of anoxic-aerobic (AA) filament bulking in nutrient removal activated sludge systems. Water Sci. Technol. 29 (7) 203-212.

EKAMA GA and MARAIS GvR (1986) Sludge settleability and secondary settling tank design. Water Pollut. Control 86 (2) 100-113.

EKAMA GA, BARNARD JL, GÜNTHERT FW, KREBS P, McCORQUODALE JA, PARKER DS and WAHLBERG EJ (1997) Secondary Settling Tanks: Theory, Modelling, Design and Operation. IWA Scientific and Technical Report No. 6, IWA, Duchess House, 20 Masons Yard, Duke Street, St. James's, London SW1Y 6BU, England.

HU ZHI-RONG, SÖTEMANN S, MOODLEY R, WENTZEL MC and EKAMA GA (2003) Experimental Investigation of the External Nitrification Biological Nutrient Removal Activated Sludge (ENBNRAS) System. Biotechnol. and Bioeng. 83 260-273.

HU ZHI-RONG, WENTZEL MC and EKAMA GA (2000) External nitrification in biological nutrient removal activated sludge systems. Water SA 26 (2) 225-238.

MARAIS GvR and EKAMA GA (1976) The activated sludge process Part I - Steady-state behaviour. Water SA 2 (4).

MULLER AW, SÖTEMANN SW, WENTZEL MC, EKAMA GA, SAAYMAN G, ESTERHUYSE K and SNYMAN K (2003) Practical implementation of external nitrification (EN) in biological nutrient removal activated sludge (BNRAS) systems. Progress Report April 2001 - December 2003 to the Water Research Commission and Water and Sanitation Services SA (Pty) Ltd on Contract No. K5/1262. Dept. Civil Eng., Univ. of Cape Town, Rondebosch 7701, South Africa.

PARKER D, LUTZ M, ANDERSSON B and ASPEGREN H (1995) Effect of operating variables on nitrification rates in trickling filters. Journal WPCF 61 (5).

PARKER D, LUTZ M, DAHL R and BERNKOPF S (1989) Enhancing nitrification rates in nitrifying trickling filters through biofilm control. Water Environ. Res. 67 (7).

SÖTEMANN SW, VERMANDE SM, WENTZEL MC and EKAMA GA (2002) Comparison of the performance of an external nitrification biological nutrient removal activated sludge system with a UCT biological nutrient removal activated sludge system. Water SA Special Edition: WISA Proceedings 2002.

WMB and BIGEN AFRICA (2000) Greater Pretoria Metropolitan Council Bulk Sanitation Strategy 2020: Evaluation of Strategic Options and Implementation of Best Strategy. 